\title{
Editorial
}

\section{William Andrés Martínez Dueñas ${ }^{1}$ Universidad del Magdalena (iD) https://orcid.org/0000-0003-0921-1149}

En este número damos continuidad al dossier "contribuciones actuales a la bioantropología latinoamericana y del caribe" liderado por el bioantropólogo Miguel Eduardo Delgado (ver editoriales del volumen 18, número 3) (Delgado, 2019; MartínezDueñas, 2019). Presentamos cinco contribuciones más, provenientes de equipos de investigación de Argentina, Colombia y México que nos hablan de paleodieta en cazadores recolectores en Colombia, así mismo se aborda de manera general el desarrollo de la bioantropología en este país y sus retos actuales. Se reporta la organización y utilización en formación e investigación, de colecciones osteológicas en Argentina y Colombia. También se presenta un estudio histórico y paleopatológico de momias del siglo XVI en México, ofreciéndonos una aproximación a las dinámicas bioculturales de la época.

En la sección general contamos con tres contribuciones de las áreas del derecho, las ciencias de la educación y la lingüística, que abarcan temas como la interculturalidad, la inclusión y la formación en ciudadanía. Es de destacar que dos de estas contribuciones evidencian la utilidad del método etnográfico en áreas se las ciencias sociales diferentes a la antropología.

Les anunciamos que la revista se encuentra migrando a un formato de publicación continua, con el ánimo de hacer disponible de la manera más ágil posible, las diferentes contribuciones que logran superar con éxito el proceso editorial. Con esto reduciremos significantemente los tiempos de publicación.

Finalmente expresamos nuestro enorme agradecimiento al comité editorial, al editor invitado y los pares evaluadores. Sin su trabajo esta publicación no sería posible. Así mismo agradecemos a la Vicerrectoría de investigación, el sello editorial y la Facultad de Humanidades de la Universidad del Magdalena por su apoyo institucional y financiero.

\section{Referencias}

Delgado, M. (2019). Contribuciones actuales a la bioantropología Latinoamericana y del Caribe. Jangwa Pana, 18(3), 358 -362. https://doi.org/10.21676/16574923.3278

Martínez, Dueñas, W. A. (2019). Los estudios bioantropológicos en Jangwa Pana. Jangwa Pana, 18(3), 363-364. https://doi.org/10.21676/16574923.3294

\footnotetext{
${ }^{1}$ Editor en jefe revista Jangwa Pana. Correo electrónico: wmartinez@ unimagdalena.edu.co.
} 